\title{
CHARACTERIZATION OF ODOURS EMITTED BY LIQUID WASTE TREATMENT PLANTS (LWTPS)
}

\author{
ZARRA T. ${ }^{1}$ \\ NADDEO V. ${ }^{1}$ \\ BELGIORNO V. ${ }^{1}$
}

Received: $20 / 07 / 2016$

Accepted: 07/09/2016

Available online: 11/10/2016

\author{
${ }^{1}$ Università degli Studi di Salerno \\ Department of Civil Engineering \\ Sanitary Environmental Engineering Division (SEED) \\ Via Giovanni Paolo II, 132, 84084 Fisciano (SA), Italy
}

*to whom all correspondence should be addressed: e-mail: tzarra@unisa.it

\section{ABSTRACT}

Odour emissions from liquid waste treatment plants (LWTPs) generally cause significant effects on the environment in terms of nuisance to exposed population. The particular and complex nature of the mixture of the volatile substances, its variability in time and the strong influence of the atmospheric conditions, are the elements that delayed their regulation and relative management.

Limited data are available in the technical and scientific literature, regarding the odour emissions characterization from liquid waste treatment plants. Moreover there isn't a common strategy from the different European Countries in the regulation of their emissions.

Different methods can be used to measure odour emissions from environmental engineering plants, and currently, in Europe, the most used techniques for odour emissions characterization and quantification is the dynamic olfactometry, according to EN 13725:2003.

The aim of this study is the characterization of the odour emissions from different liquid waste treatment plants (LWTPs), through a case study of two large real LWTPs, in order to identify the principal odour sources and to define their related odour emissions.

Odour Concentration Index $(\mathrm{OCI})$ is proposed as a useful and simply odour management tool for the identification of the priority actions necessary to identify and control the main odorous sources. Relationship between the measured odour emissions and the types of treated liquid waste (identified in terms of EWC code, COD and $\mathrm{NH}^{+}$) is also discussed.

Results show that the influent collection tank is the source with the highest detected odour emissions. $\mathrm{OCI}$ results are useful for the definition of a clear priority action for odour control, similar for both investigated plants. Between the characterized types of liquid waste treated by LWTPs the leachate (EWC 190703) show the maximum odour emissions.

Keywords: dynamic olfactometry, European Waste Catalogue (EWC), EN13725:2003, leachate, odor monitoring.

\section{Introduction}

In recent years the need for treatment of liquid waste, coming from the most varied industrial activities, has grown considerably (Belgiorno et al., 2012). Their treatment generally occurs in authorized wastewater treatment plants. Liquid waste, in terms of EU regulations, are identified and disposed in authorized treatment plants according to EWC code (European Waste Catalogue). 
In the technical and scientific literature regarding the issue of odours emitted by liquid waste treatment plants limited data are available. The problems related to odor emissions from environmental engineering facilities are among the leading causes of annoyance for the exposed population living surrounding at the plants, in account of the immediacy of perception, instantly linked to unhealthy environmental conditions (Dalton, 2002; Zarra et al., 2008; Sucker et al., 2009; Aatamila et al., 2011; Naddeo et al., 2012). Moreover there isn't a common strategy from the different European Countries in the regulation of their emission (Stuetz et al., 2001; Zarra et al., 2008; Sironi et al., 2012).

Odour measurement are carried out using sensorial, analytical or mixed methods, after a sampling phase. In Europe the most used techniques for the characterization of the odour concentration and the quantification of the odour emissions is the dynamic olfactometry, according to EN 13725:2003 (Nicell, 2009; Zarra et al., 2014). This method is based on sensorial technique and it avails of an instrument of dilution, the olfactometer, in order to submit odor, at different concentration levels, to a set of evaluators (panel). The EN 13725:2003 standard 'Air Quality - Measurement of odour concentration using dynamic olfactometry', is presently being revised by a working group of experts, CEN/TC264/WG2 'Olfactometry' (Van Harreveld, 2014).

Recent studies proposed the use of novel tools for the control of the odour concentration and emissions, such as the measurement of Odour Emission Capacity (OEC) (Giuliani et al., 2015) or the use of e-noses (Zarra et al., 2014).

The aim of the study is the characterization of the odour emissions from different liquid waste treatment plants (LWTPs), trough a case study of two large real LWTPs, in order to identify the principal odour sources and to define their related odour emissions. Odour Concentration Index $(\mathrm{OCl})$ is proposed as a useful and simply odour management tool for the identification of the priority actions necessary to identify and control the main odorous sources. Relationship between the measured odour emissions and the types of treated liquid waste, in terms of EWC code, is also discussed.

\section{Materials and methods}

\subsection{Liquid waste treatment plants (LWTPS)}

Research studies were carried out at two large real liquid waste treatment plants (LWTPs), located in the municipality of Buccino (B) and Palomonte (P), in the Salerno Province, in the Campania Region (Southern Italy). Both plants were initially designed for the treatment of industrial wastewater and only in the recent years they were adapted and authorized also to the treatment of non-hazardous liquid waste. The principal design characteristics of the investigated LWTPs are shown in Table 1.

The main treated liquid waste types of both plants are leachate from landfill (EWC 190703), sludges from dairy waste (EWC 020502) and leachate from refuse derived fuel (RDF) plants (EWC 161002).

Table 1. Design characteristics of the investigated LWTPs.

\begin{tabular}{lcc}
\hline \multicolumn{2}{c}{ Parameter } & \multicolumn{2}{c}{ LWTP } \\
\cline { 2 - 3 } & Buccino & Palomonte \\
\hline average daily flow & $6600 \mathrm{~m}^{3} \mathrm{~g}^{-1}$ & $108 \mathrm{~m}^{3} \mathrm{~h}^{-1}$ \\
\hline $\mathrm{BOD}_{5}$ & $3600 \mathrm{~kg} \mathrm{~g}^{-1}$ & $1690 \mathrm{~kg} \mathrm{~g}^{-1}$ \\
\hline $\mathrm{COD}$ & $7200 \mathrm{~kg} \mathrm{~g}^{-1}$ & $3380 \mathrm{~kg} \mathrm{~g}^{-1}$ \\
\hline max treatment capacity of non-hazardous liquid waste & $300 \mathrm{tg}^{-1}$ & $200 \mathrm{t} \mathrm{g}^{-1}$ \\
\hline
\end{tabular}

\subsection{Sampling program}

Odour samples were taken every month at 6 different treatment units in each LWTP for a period of 12 consecutive months, from January 2014 to January 2015. Figure 1 shows the identification of the investigated treatment units for both plants. 
Lung technique was implemented for the air sampling at selected emission points, using a vacuum pump in accordance with EN 13725:2003. 10 L volume of Nalophan ${ }^{\circledR}$ bags were used for the sampling. Passive areal sources are sampled using the SF450 flux chamber (Scentroid, CDN).

In order to investigate the relationship between the emitted odour concentration and the types of liquid waste, were also monthly collected the liquid waste samples of the main three abundant waste types at the influent point and its relative odour emission. Liquid waste samples were collected according to the APAT IRSA CNR 1030 MAN 29/03 method, taking a sample of $10 \mathrm{~L}$ in an amber glass container.

A total of 216 air samples and 72 liquid waste samples were collected of both plants in the investigated period.
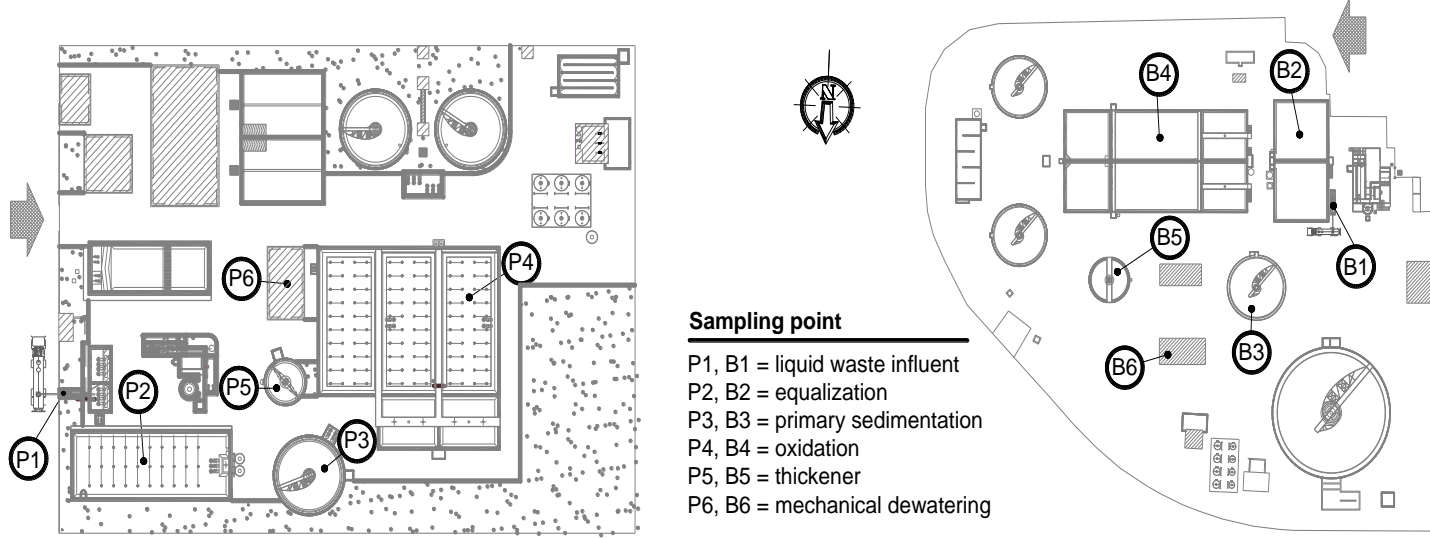

Figure 1. Sampling points at investigated LWTPs (Palomonte (P), left; Buccino (B), right)

\subsection{Analysis}

Collected air samples were characterized by dynamic olfactometry according to EN 13725:2003, determining the odour concentration in terms of $\mathrm{OU} \mathrm{m}^{-3}$. Olfactometric analyses were conducted at the Olfactometric Laboratory of the SEED (Sanitary Environmental Engineering Division) at Universià degli Studi di Salerno (Italy), using the olfactometer model TO8 by ECOMA. All samples were analysed within 14 hours after sampling (Zarra et al 2012a), relying on a panel composed of 4 trained panelists and applying the "yes/no" method. Odour Concentrations (Cod) were also compared in terms of Odour Index (OI) calculated with the following equation:

$$
\mathrm{Ol}=10 \log (\mathrm{Cod})
$$

Liquid waste samples were characterized in terms of COD and ammonia $\left(\mathrm{NH}^{+}\right)$following the Standard Methods APAT IRSA CNR MAN 29/03 respectively according to Section 5130 and Section 4030.

\subsection{Odour Concentration Index (OCI) of odours sources}

To compare the results was introduced the Odour Concentration Index $(\mathrm{OCI})$ and the Priority Action for odour Control (PAC) of odours sources.

$\mathrm{OCl}$ at the source $S_{i}$ is calculated with the following equation:

where:

$$
\mathrm{OCl}_{\mathrm{si}}=\left[75^{\circ} \mathrm{p}\left(\mathrm{Cod}_{\mathrm{si}}\right) / \mathrm{Cod}_{\mathrm{am}}\right]
$$

- $75^{\circ} \mathrm{p}\left(\mathrm{Cod}_{\mathrm{si}}\right)$ is the $75^{\circ}$ percentile of Odour Concentration (Cod) measured at the source $\mathrm{S}_{\mathrm{i}}$;

- $\operatorname{Cod}_{\mathrm{am}}$ is the admissible concentration at emission point, that in this study, in absence of national limit, was fixes at $300 \mathrm{OU} \mathrm{m}^{-3}$ according to Lombardia Region Law that limit the odour emission from biofilters.

$\mathrm{OCl}$ define the ranking between the different sources in terms of odour emission and give strategic information for odour control and management in the plant.

Priority Action for odour Control (PAC) is the ranking order of each odorous source according to calculated $\mathrm{OCl}$. 


\section{Results and discussion}

\subsection{Odour emission characterization}

Variability of odour concentrations at investigated treatment units over the monitored period was reported in Figure 2.
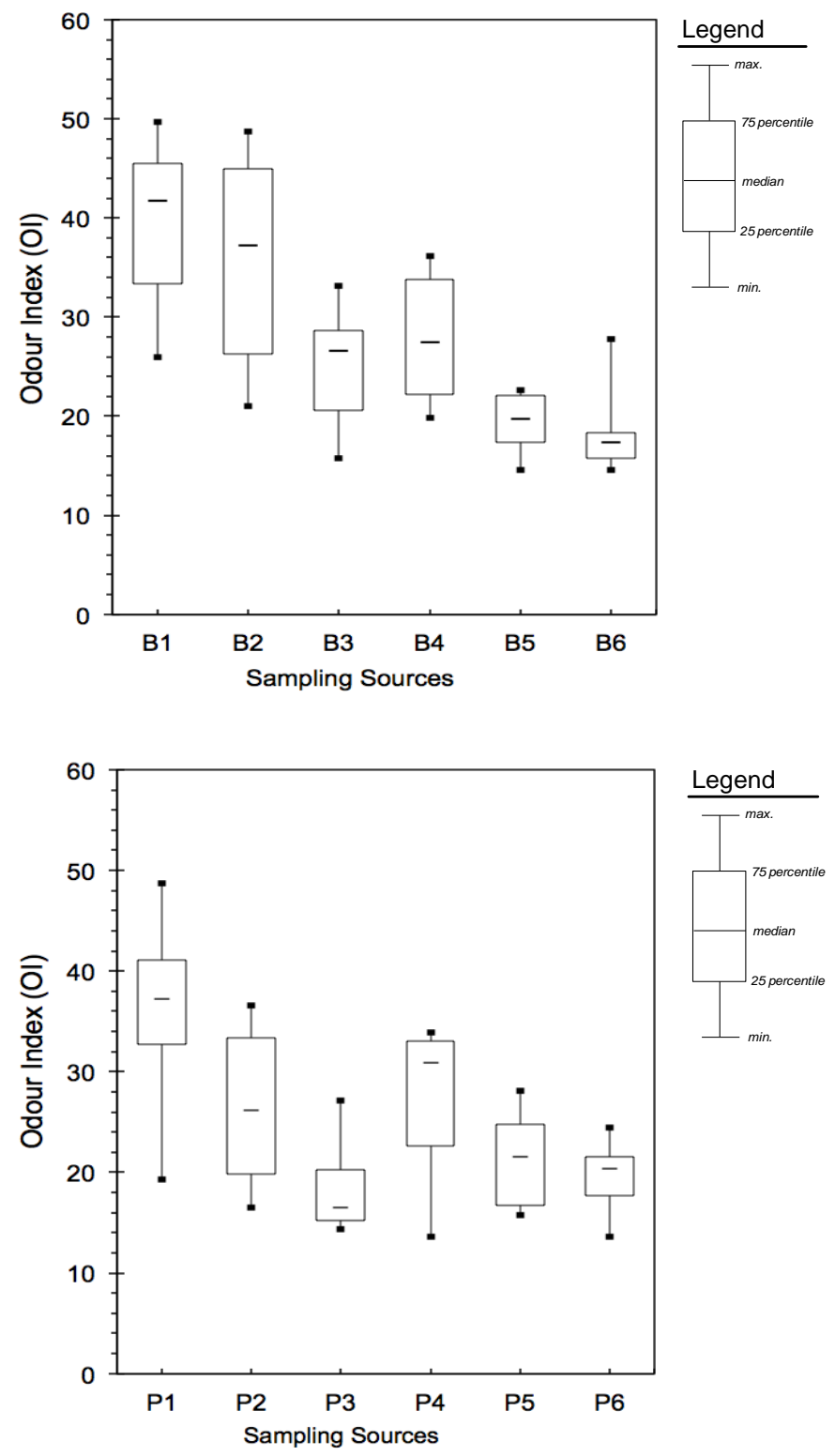

Figure 2. Box-Whisker diagrams on measured odour concentrations at Buccino LWTP (left) and at Palomonte LWTP (right)

Results show that at the LWTP of Buccino the highest odour concentration $\left(C_{\text {od }}=92^{\prime} 682 \mathrm{OU} \mathrm{m}^{-3}\right)$ was detected at liquid waste influent (B1), while the lowest $\left(C_{o d}=29 \mathrm{OU} \mathrm{m}^{-3}\right)$ at the sludge treatments (B5, B6). Similarly at the LWTP of Palomonte the liquid waste influent point has registered the highest odour emission concentration $\left(C_{o d}=73^{\prime} 562 \mathrm{OU} \mathrm{m}^{-3}\right)$, while the lowest odour concentration was detected at the mechanical dewatering and the oxidation treatments $\left(\mathrm{C}_{\mathrm{od}}=23 \mathrm{OU} \mathrm{\textrm {m } ^ { - 3 }}\right)$. The source that highlights the major variability was in both plants the influent liquid waste thank, while the thickening in the Buccino LWTP and the mechanical dewatering in the Palomonte LWTP were the sources with more stable emitted concentrations of odours. 
Figure 3 shown the relation of $\mathrm{COD}$ and $\mathrm{NH}^{+}$versus odour index (OI) for each liquid waste, identified in terms of EWC code, investigated in both plants at influent point. With reference to ammonia content, leachate from landfill (EWC 190703) have high variability and high content of ammonia. On other hand sludges from dairy waste (EWC 020502) and leachate from refuse derived fuel (RDF) plants (EWC 161002) have limited variability of ammonia and generally lower odour concentration at emission sources.

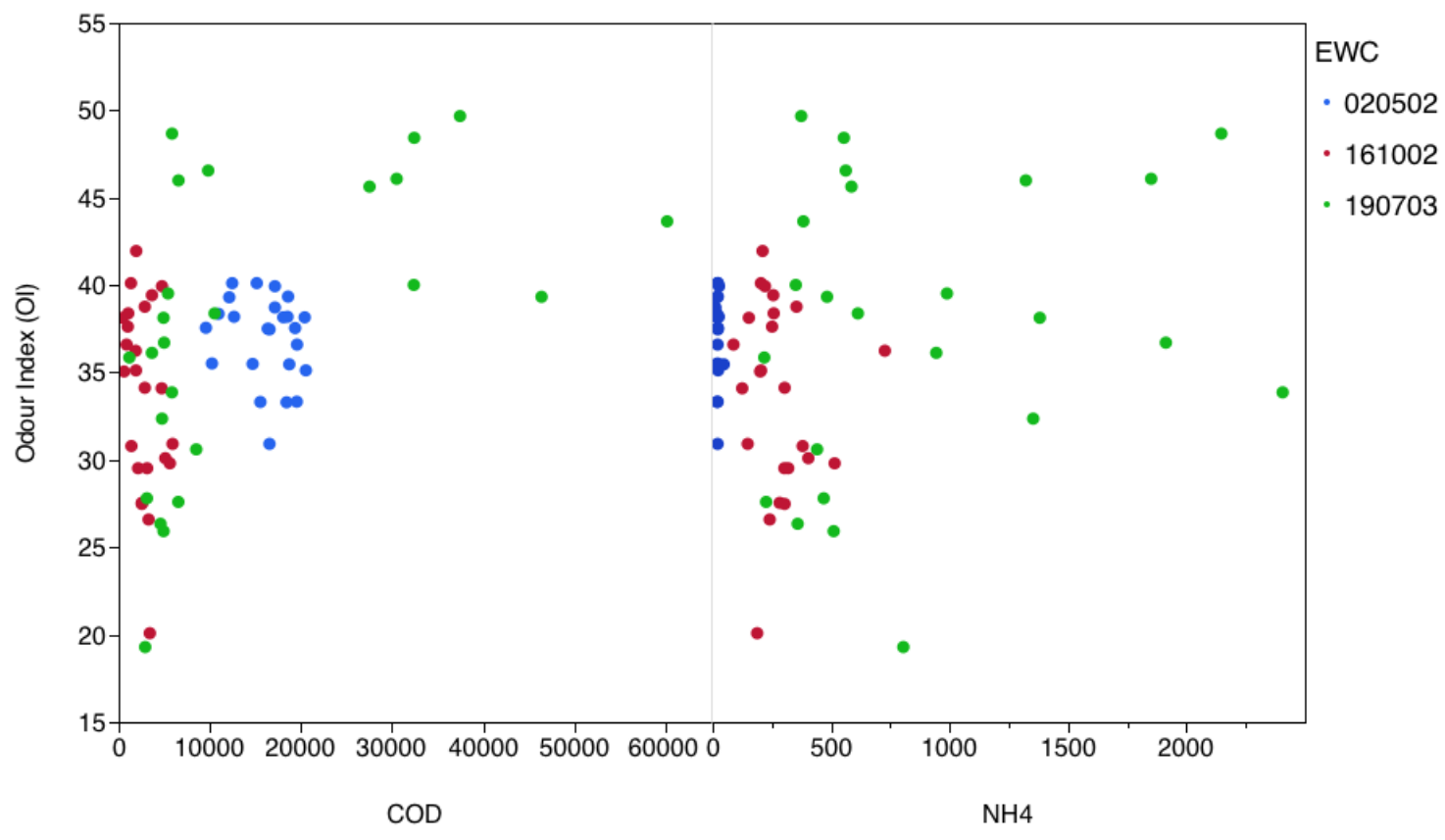

Figure 3. Characterization of Odour Index (OI) versus COD $\left(\mathrm{mg} \mathrm{l}^{-1}\right)$ and Ammonia $\left(\mathrm{mg} \mathrm{l}^{-1}\right)$ for each investigated EWC code in both plants

In terms of COD the results are more stable with exception of some points of leachate from landfill (EWC 190703) that have very high content of COD.

Comparing the results of odour emissions monitored in both LWTPs with the odour concentration generally emitted by conventional wastewater treatment plants (Gostelow et al., 2001; Zarra et al., 2008; Zarra et al., 2009; Lebrero et al., 2011; Zarra et al., 2012b; Lehtinen et al., 2012), it can see that the emissions are higher for the wastewater line treatments. While for the sludge treatments in the investigated LWTPs the measured odour concentrations are lower than those generally detected at conventional wastewater treatment plants (WWTPs). As reported in Zarra et al. (2008) studies in fact, in conventional WWTPs the odour sources with the higher emitted odour concentrations are coming from sludge line such as the mechanical dewatering $\left(4000-20000 \mathrm{OU} \mathrm{m}^{-3}\right)$ and the thickening $(2000-12000$ $\mathrm{OU} \mathrm{m}^{-3}$ ), followed by the preliminary treatments. The primary and secondary wastewater treatment units are usually characterized by lower and more constant odour concentration at emission sources.

\subsection{Odour Concentration Index (OCI) of odours sources}

Table 2 show the Odour Concentration Index (OCI) and the Priority Action for odour Control (PAC) for all monitored treatment units in both plants.

The results show that for both plants the liquid waste influent tank is the treatment unit that need some Priority Action for odour Control before all others units. In addition, according to calculated $\mathrm{OCI}$ between all monitored treatment units, only 2 odour sources for each plant have odour concentrations, in terms of their $75 \%$ percentile, lower to fixed admissible odour limit. Obtained results highlights differences with the odour concentration measured at the conventional WWTPs, in which the highest $75^{\circ} \mathrm{p}$ Cod were generally detected at the sludge line (Zarra et al., 2008) and where if we try to calculate the proposed OCI 
and PAC, the units with higher priority of action would be located in the sludge line, oppositely to those related to the investigated LWTPS.

Table 2. Characterization of treatment units for both plants in terms of $\mathrm{OCl}$ and PAC.

\begin{tabular}{cccccccc}
\hline & \multicolumn{1}{c}{ LWTP } & \multicolumn{2}{c}{ Buccino } & \multicolumn{3}{c}{ Palomonte } \\
\hline ID & Sampling point & $\mathbf{7 5}^{\mathbf{0}} \mathbf{p}$ Cod $\left[\mathbf{O U} \mathbf{~ m}^{-3}\right]$ & OCI & PAC & $\mathbf{7 5}^{\circ} \mathbf{p ~ C o d ~}\left[\mathbf{O U} \mathbf{~ m}^{-3}\right]$ & OCI & PAC \\
\hline 1 & Liquid waste influent & 35587 & 118,6 & 1 & 12894 & 43,0 & 1 \\
\hline 2 & Equalization & 31661,5 & 105,5 & 2 & 2173 & 7,2 & 2 \\
\hline 3 & Primary sedimentation & 724 & 2,4 & 4 & 107 & 0,4 & - \\
\hline 4 & Oxidation & 2370,5 & 7,9 & 3 & 2006 & 6,7 & 3 \\
\hline 5 & Thickener & 162,25 & 0,5 & - & 298 & 0,9 & - \\
\hline 6 & Mechanical dewatering & 67,5 & 0,2 & - & 143 & 0,5 & - \\
\hline
\end{tabular}

\section{Conclusions}

Odours concentration emitted by LWTPs generally are higher of the odours measured at the conventional wastewater treatment plant. The proposal and the use of the Odour Concentration Index (OCI) highlights that only few sources for the investigated LWTPs have an acceptable odour concentration at emission points $(\mathrm{OCl}<1)$.

In both investigated LWTPs the odour source with the highest detected odour concentration are localized in the initial treatment units (the liquid waste influent tank and the equalization basin). The Priority Action for odour Control (PAC) index give a clear priority list of actions needs in the plant for the implementation of effective odour control strategy.

Additional studies are needed to investigate the plants that treat different type of liquid waste and to analyze the possible correlation between the content of organic substance in the liquid waste versus the their odour emission capacity (OEC).

\section{References}

Aatamila M., Verkasalo P.K., Korhonen M.J., Suominen A.L., Hirvonen M.R., Viluksela M.K. and Nevalainen A. (2011), Odour annoyance and physical symptoms among residents living near waste treatment centres, Environmental Research, 111(1), 164-170.

Belgiorno V., Naddeo V. and Zarra T. (2012), Odour Impact Assessment Handbook, Wiley \& Son. London. ISBN: 9781-119-96928-0.

Dalton P. (2002), Olfaction in Yantis, in Handbook of Experimental Psychology, S. Stevens, 1, 691-746.

EN 13725:2003 (2003), Air Quality e Determination of Odour Concentration by Dynamic Olfactometry, Comité Européen de Normalisation, Brussels, 1 - 70.

Giuliani S., Zarra T., Naddeo V. and Belgiorno V. (2015), A novel tool for odor emission assessment in wastewater treatment plant, Desalination and Water Treatment, 55(3), 712-717.

Gostelow P., Parsons S.A. and Stuetz R.M. (2001), Odour measurements for sewage treatment works, Water Res., 35, 579-597

Lebrero R., Bouchy L., Stuetz R. and Muñoz R. (2011), Odor Assessment and Management in Wastewater Treatment Plants: A Review, Critical Reviews in Environmental Science and Technology, 41(10), 915-950, DOI: 10.1080/10643380903300000.

Lehtinen J., Giuliani S., Zarra T., Reiser M., Naddeo V., Kranert M., Belgiorno V., Romain A.C., Nicolas J., Sówka I., Wang K.Y., Kalogerakis N. and Lazaridis M. (2012), Case Studies for Assessment, Control and Prediction of Odour Impact, in Odour Impact Assessment Handbook (eds V. Belgiorno, V. Naddeo and T. Zarra), John Wiley \& Sons, Inc., Hoboken, NJ, USA. doi: 10.1002/9781118481264.ch8.

Naddeo V., Belgiorno V. and Zarra T. (2012), Odour Characterization and Exposure Effects in Odour Impact Assessment Handbook, Wiley \& Son. London. ISBN: 978-1-119-96928-0, 7-29. 
Nicell J.A. (2009), Assessment and regulation of odour impacts, Atmospheric Environment, 43, 196-206.

Sironi S., Capelli L., Dentoni L. and Del Rosso R. (2012), Odour Regulation and Policies in in Odour Impact Assessment Handbook, Wiley \& Son. London. ISBN: 978-1-119-96928-0, 175-186.

Sucker K., Both K. and Winneke G. (2009), Review of adverse health effects of odours in field studies, Water Science and Technology, 59, 1281-1289.

Van Harreveld A.P. (2014), Progress in the review of EN13725: focus on sampling and uncertainty, Chemical Engineering Transactions, 40.

Zarra T., Naddeo V., Belgiorno V., Reiser M. and Kranert M. (2008), Odour monitoring of small wastewater treatment plant located in sensitive environment, Water Science and Technology, 58(1), 89-94.

Zarra T., Naddeo V., Belgiorno V., Reiser M. and Kranert M. (2009), Instrumental characterization of odour: a combination of olfactory and analytical methods, Water Science and Technology, 59(8), 1603- 1609.

Zarra T., Reiser M., Naddeo V., Belgiorno V. and Kranert M. (2012a), A comparative and critical evaluation of different sampling materials in the measurement of odour concentration by dynamic olfactometry, Chemical Engineering Transactions, 30, 307-312.

Zarra T., Giuliani S., Naddeo V. and Belgiorno V. (2012b), Control of odour emission in wastewater treatment plants by direct and undirected measurement of odour emission capacity, Water Science and Technology, 68(8), 1627- 1633.

Zarra T., Reiser M., Naddeo V., Belgiorno V. and Kranert M. (2014), Odour Emissions Characterization from Wastewater Treatment Plants by Different Measurement Methods, Chemical Engineering Transactions, 40, 37-42. 